\title{
Tratado das degenerescências na espécie humana*
}

Benedict-Augustin Morel

\section{Prolegômenos \\ Primeira seção}

$\mathrm{I}-\mathrm{O}$ que se deve entender por degenerescência na espécie humana?

- Definição da palavra degenerescência

Apesar das tão numerosas causas de destruição que ameaçam a conservação da espécie humana, sua propagação sob as mais diversas latitudes, a variedade de aptidões intelectuais, físicas e morais que caracterizam o indivíduo e a raça segundo as condições que presidem seu desenvolvimento, são fatos tão evidentes, tão universalmente aceitos, que não há necessidade de nenhuma demonstração.

* Tradução de Maria Vera Pompeo de Camargo Pacheco. Revisão técnica do Prof. Dr. Mário Eduardo Costa Pereira, ambos do Laboratório de Psicopatologia Fundamental da UNICAMP, texto retirado de Traité des dégénérescences physiques, intelectuelles et morales de l'espèce humaine et les causes qui produisent ces variétés maladives. Paris: Baillière, 1857. As notas de rodapé foram mantidas como no original. 
A existência de um tipo primitivo que o espírito humano tem prazer em constituir em seu pensamento como a obra-prima e a síntese da criação é um outro fato tão de acordo com nossas crenças que a idéia de uma degenerescência de nossa natureza é inseparável da idéia de um desvio desse tipo primitivo, que encerrava em si mesmo os elementos da continuidade da espécie.

Esses fatos, que em nossa época receberam a tripla sanção da verdade revelada, da filosofia e da história natural, me servirão de introdução ao relato daquilo que se deve entender por degenerescência na espécie humana.

O Homem não é nem produto do acaso e nem manifestação última de pretensas transformações incompatíveis com as mais banais noções sobre a sucessão das espécies segundo seu tipo primitivo. ${ }^{1}$

Criado para atingir o objetivo designado pela sabedoria eterna, o Homem não pode fazê-lo se as condições que asseguram a duração e o progresso da espécie humana não fossem ainda mais potentes do que as que contribuem para destruíla e fazê-la degenerar.

Essa idéia de causas de destruição e de degradação da espécie humana é uma das mais largamente difundidas; ela forma a base de uma grande quantidade de sistemas filosóficos e religiosos; ela existe, inclusive, entre a maior parte dos grandes mestres da ciência médica como uma dessas crenças instintivas que são a expressão dos fatos menos susceptíveis de serem contestados: "Assim é, exclama Bichat, o modo de existência de seres vivos, que tudo o que os rodeia tende incessantemente a destruí-los".

É o antagonismo entre os seres inertes e os seres vivos; mas esse próprio antagonismo é interpretado diversamente em seu ponto de partida e em suas conseqüências, segundo a divergência de doutrinas e de sistemas.

1. Nos três primeiros capítulos da Gênesis, a lei que assegura a continuidade da espécie segundo sua forma primitiva é anunciada em três lugares diferentes, tanto para o que concerne as espécies animais, como as espécies vegetais: Dixit Deus producat terra animam viventem in genere suo, jumenta et reptitia et bestias terrae secundum species suas (Gênesis, c. II, v. 24). Ecce dedi vobis omnem herbam afferentem semen super terram et universa ligna quae habent in semet ipsis sementem generis sui (C. III, v. 29. Ver também o cap. II, v. 12).

É fato dos mais evidentes que no mundo animal, assim como no mundo vegetal, geralmente todas as raças reproduzem-se e perpetuam-se sem se misturar e nem se confundir umas com as outras. A lei da natureza propõe que as criaturas de todos os tipos cruzem e multipliquemse propagando sua própria espécie e não qualquer outra; e provavelmente seria em vão que se procurasse no mundo inteiro um exemplo bem comprovado de uma raça intermediária proveniente de duas espécies devidamente reconhecidas como distintas. Um fato desse gênero, se viéssemos a descobri-lo, certamente constituiria uma surpreendente anomalia (Dr. Prichard Histoire naturelle de l'homme, Paris, 1845, tomo $1^{\circ}$, p. 17). 
Se alguns filósofos, como Rousseau, Condillac e a maior parte de seus adeptos, viram nesse antagonismo apenas a influência das instituições sociais em desacordo com a natureza, outros atribuíram todas as imperfeições da saúde e todas as misérias de nosso estado físico à depravação da natureza moral.

E ainda, para alguns outros, a explicação do fato reside exclusivamente na degradação original da natureza humana.

Penso como o autor dos Etudes de Médécine Générale, ${ }^{2}$ que a opinião intermediária é mais próxima da verdade e mais fecunda em resultados no interesse das pesquisas que eu próprio desenvolvo: é a que admite a degradação original da natureza humana, agindo sozinha ou com a ajuda de circunstâncias exteriores, instituições sociais e de todas as influências ocasionais e análogas.

Tenho motivos para acreditar que essa opinião será facilmente admitida por todos os que pensam, como eu, que a difícil questão das degenerescências na espécie humana deve ser estudada em sua origem, e ter seqüência no exame científico das novas condições que o grande acontecimento da queda original veio criar para o homem.

Colocado nessas novas condições, o homem primitivo sofreu todas essas conseqüências, e seus descendentes não puderam escapar nem à influência da hereditariedade, nem à de todas as causas que, alterando sua saúde, tenderam cada vez mais a fazê-lo desviar do tipo primitivo.

Esses desvios trouxeram variações, das quais algumas constituíram raças capazes de se transmitir com uma característica típica especial; e outras criaram esses estados anormais nas diversas raças, que constituirão o objeto especial desses estudos e que designo pelo nome de degenerescências. Essas degenerescências também têm sua marca típica; elas distinguem-se umas das outras pelo fato de que certas causas mórbidas que atingem profundamente o organismo produzem tal degenerescência com prioridade, ao invés de tal outra; elas formam grupos ou famílias que vão buscar seus elementos diferenciadores na própria natureza da causa que as produziu.

As degenerescências não podem, portanto, ser mais que o resultado de uma influência mórbida, seja de ordem física, seja de ordem moral, e, como todos os estados doentios, têm suas características especiais e suas características gerais.

Uma das características mais essenciais das degenerescências é a da transmissão hereditária, mas em condições bem diferentemente graves do que as que regulamentam as leis comuns da hereditariedade. A observação rigorosa dos fatos nos demonstrará que, salvo em certas circunstâncias excepcionais de regeneração, os produtos de seres degenerados oferecem tipos de degradação

2. Tessier. Études de médécine générale, Paris, $1855,1^{\text {a }}$ parte, p. 38. 
progressiva. Essa progressão pode alcançar limites tais, que a humanidade só encontra-se preservada pelo próprio excesso do mal, e a razão disso é simples: a existência dos seres degenerados é necessariamente restringida, e, coisa maravilhosa, não é sempre necessário que eles cheguem ao último grau da degradação para que sejam marcados pela esterilidade e, conseqüentemente, incapazes de transmitir seu tipo de degenerescência.

Desse simples relato resulta que a mais clara idéia que poderíamos formar da degenerescência de espécie humana é a de representá-la como um desvio doentio de um tipo primitivo. Esse desvio, por mais simples que seja suposto em sua origem, encerra, no entanto, elementos de transmissibilidade de tal natureza que aquele que carrega seu germe torna-se cada vez mais incapaz de cumprir sua função na humanidade, e que o progresso intelectual já bloqueado em sua pessoa, encontra-se ainda ameaçado na de seus descendentes.

Portanto, em minha concepção, degenerescência e desvio doentio do tipo normal da humanidade são uma única e mesma coisa, e talvez a idéia que exprimo aqui se distancie da que alguns fisiologistas parecem ter desse estado mórbido, especialmente Frédéric Heusinger em seu excelente Traité de pathologie comparée. O sentido que esse sábio autor atribui ao que chama de degeneração na espécie animal apóia-se no seguinte fato.

Nós sabemos que as raças domésticas podem ser submetidas por habilidade a certas influências, e que essas mesmas influências, favorecendo uma evolução especial, conduzem aptidões que se acredita convocarem um aperfeiçoamento; mas a observação nos ensina também que a natureza sempre mostra uma tendência a voltar à organização da espécie; e essa lei aplica-se tão bem às plantas, como aos animais.

Tal retorno da variedade a seu tipo original, em minha opinião, foi chamado erroneamente de degeneração por Frédéric Heusinger. Essa tendência da animalidade de voltar a seu tipo normal, além do mais, é bastante indicativa de que a modificação impressa no animal por habilidade do criador é mais fictícia que real. $^{3}$

3. A cada dia fazemos novas raças de animais domésticos. Nós as fazemos quando queremos. Não é tudo: uma vez feitas essas raças, nada é mais difícil do que impedi-las, se assim posso dizer, de desfazer-se. Há uma arte, e muito complicada, que não tem outra meta além de conservar as raças.

Nossos cães, nossos cavalos, tornados livres na América, voltaram a uma cor uniforme, a um tipo único. O cachorro perdeu seu latido e recuperou suas orelhas retas. O porco voltou a ser javali. (Fourens. Histoire des travaux et des idées de Buffon, Paris, 1850, p. 170). 
Por outro lado, no estado que designo pelo nome de degenerescência, não se nota essa propensão do indivíduo de retornar ao seu tipo normal, pelo fato de que a degenerescência é um estado morbidamente constituído e que o ser degenerado, se for abandonado a si próprio, cai numa degradação progressiva. Torna-se (e não temo repetir essa verdade), torna-se, não somente incapaz de formar na humanidade a cadeia de transmissibilidade de um progresso, mas é também o maior obstáculo a esse progresso, por seu contato com a parte sadia da população. A duração de sua existência é enfim limitada, como a de todas as monstruosidades.

Depois desse sucinto relato sobre o que é preciso entender pela palavra degenerescência na espécie humana, resta-me expor o plano que segui numa obra semeada de dificuldades, tanto maiores em razão de que mesmo que muito se tenha escrito sobre diferentes variedades de seres degenerados, nenhum autor, que eu saiba, empreendeu ainda a tarefa de teorizar sobre tudo o que tem relação com as causas distantes ou próximas das degenerescências, de estabelecer as classificações de seus produtos e de formular as regras gerais da profilaxia, da higiene e do tratamento. A ajuda desses elementos torna possível combater-se o conjunto de causas de destruição e de abastardamento da espécie humana.

Modo de produção de seres degenerados, classificação, profilaxia, higiene e tratamento são os termos nos quais vão se concentrar todas as minhas pesquisas.

Vou, portanto, expor aqui o plano que elaborei, as dificuldades que tive que vencer, assim como todas os embaraços que me importunaram na coordenação desse trabalho. Eu o farei sucintamente e com a maior simplicidade possível, convencido de que essa franqueza de minha parte tornará o leitor mais simpático a essa obra, e o disporá a suprir com suas próprias reflexões as numerosas lacunas que me foi impossível evitar.

Benedict-Augustin Morel (1809-1873)

Alienista francês que primeiro descreveu a demência precoce. 